\title{
Effects of Task-Specific Obstacle Crossing Training on Functional Gait Capability in Patients with Cerebellar Ataxia: Feasibility Study
}

Jin-Hoon Park

Department of Physical Education, College of Education, Korea University, Seoul, Korea

Purpose: The purpose of this study was to examine the effects of a task-specific obstacle crossing rehabilitation program on functional gait ability in patients with cerebellar ataxia. Overall, we sought to provide ataxia-specific locomotor rehabilitation guidelines for use in clinical practice based on quantitative evidence using relevant analysis of gait kinematics including valid clinical tests.

Methods: Patients with cerebellar disease $(n=13)$ participated in obstacle crossing training focusing on maintenance of dynamic balance and posture, stable transferring of body weight, and production of coordinated limb movements for 8 weeks, 2 times per week, 90 minutes per session. Throughout the training of body weight transfer, the instructions emphasized conscious perception and control of the center of body stability, trunk and limb alignment, and stepping kinematics during the practice of each walking phase.

Results: According to the results, compared with pre-training data, foot clearance, pre-Etpost-obstacle distance, delay time, and total obstacle crossing time were increased after intervention. In addition, body COM measures indicated that body sway and movement variability, therefore posture stability during obstacle crossing, showed improvement after training. Based on these results, body sway was reduced and stepping pattern became more consistent during obstacle crossing gait after participation in patients with cerebellar ataxia. Conclusion: Findings of this study suggest that task-relevant obstacle crossing training may have a beneficial effect on recovery of functional gait ability in patients with cerebellar disease.

Keywords: Obstacle crossing, Cerebellar ataxia, Motor relearning

\section{서 론}

소뇌성 운동실조증(cerebellar ataxia)은 소뇌 영역을 비롯해 관련 입 출력 신경회로의 구조적 변성으로 말미암아 나타나는 운동이상 증 상으로 다양한 신경학적 증후들을 복합적으로 동반하며 근육 간 협 응불능(dyssynergia), 분절화된 움직임(decomposition), 그리고 거리측 정이상(dysmetria) 등과 같은 운동장애 증상을 특징적으로 나타낸다 고 알려져 왔다. 특히, 퇴행성 소뇌질환을 않고 있는 환자들의 경우 운동능력의 점진적 저하로 말미암아 궁극적으로 독립적인 움직임과 실생활 유지에 많은 곤란을 겪을 수 있으며, 환자들의 삶의 질(quality of life)에 있어 부정적인 영향을 미칠 수 있다고 밝히고 있다. 즉, 소뇌 성 운동실조증으로 인한 운동장애는 환자들의 신체적 결손뿐만 아 니라 그들의 심리적·사회적 측면에서의 어려움까지도 유발할 가능

Received April 9, 2015 Revised April 15, 2015

Accepted April 19, 2015

Corresponding author Jin-Hoon Park

E-mail jpark12@korea.ac.kr
성이 높다고 할 수 있다.

다른 신경계질환(예, 뇌졸중) 환자의 균형 및 보행과 관련한 재활 연구는 다수 있으나,-6 소뇌성 운동실조증에 대한 운동 재활 관련 연 구나 임상적 증거는 상대적으로 부족한 실정이다. 이는 낮은 유병률 과 장애의 양상 및 정도가 환자에 따라 상이한(heterogeneous) 점 등 이 제한적인 연구적 관심과 노력의 원인이 되고 있다. 이로 인해 아직 까지 환자들에게 적용할 수 있는 효과적인 의학적 치료법이 개발되 지 않았으나, 최근 치료적 운동재활 접근방법(physiotherapeutic approaches)이 소뇌성 운동실조증 환자들의 기능적 회복에 긍정적인 결 과를 미칠 수 있다는 근거가 제시되고 있다. ${ }^{7}$ 비록 적은 수이기는 하 나 치료적 운동재활 요법의 효과를 검증한 임상 연구의 결과에 따르 면 비교적 강도 높은 균형과 보행 훈련을 집중적으로 실시하였을 때 증가된 자세 안정성과 일상생활에서의 보행 보조기구에 대한 의존 
성 감소 등의 개선이 나타나는 것으로 보고되고 있다. ${ }^{8} \mathrm{Ilg}$ 와 Tim$\mathrm{mann}^{9}$ 정적 및 동적 균형 활동과 전신협응 움직임으로 구성된 운동 활동 중재 훈련이 소뇌질환 환자들의 보행과 균형 기능의 회복을 강 화한다고 보고하고 있으며, 훈련기간 동안 점진적으로 수행의 난이 도를 증가시키면서 다양한 동작과제를 집중적이고 높은 강도로 실시 하는 것이 중요하다고 제안하였다. 하지만 아직 소뇌질환 환자들을 위한 재활 운동치료에 있어서 명백한 연구 및 임상적 증거에 입각한 구체적 훈련 지침이나 전략을 제공한 연구는 많지 않다.

운동학습 분야와 신경변성을 유도한 동물을 대상으로 한 신경재 활 연구의 결과는 소뇌성 운동실조증 환자들의 기능 회복과 재활 운 동프로그램의 최적화를 위한 임상적 원리와 시사점을 제시하고 있 다. 특히 회복하고자 하는 운동기능과 관련성이 높은 운동요소들을 중심으로 훈련 과제를 구성하여 이를 직접적으로 연습하는 과제 특 수성(task-specific) 원리를 적용한 재활 프로그램이 목표로 하는 기능 의 향상과 그에 따른 연관된 신경의 가소성(plasticity)을 촉진하는 것 으로 알려져 있다. ${ }^{10}$ 예를 들어, 이동운동을 위한 재활 프로그램은 일 차적으로 훈련의 구성 요소가 실제 보행 과제와 밀접히 연결될 때 보 행 능력의 기능적 회복에 있어 더욱 효과적일 수 있다고 제안한다."

하지만 아직까지 이러한 과제 특수성 원리를 일상생활 중 흔히 맞 닥뜨리는 장애물(예, 보도블럭의 턱, 계단, 문지방 등)을 안전하고 효 과적으로 넘는 기능을 향상시키기 위한 재활 프로그램에 적용된 예 는 드물다. 일반 평지 보행과 비교하였을 때, 장애물 보행은 장애물 특 성(예, 높이, 너비 등)에 대한 지각과 신체 평형 유지, 그리고 하지의 제 어와 협응의 요구가 더 높은 복잡하고 기능적인 동작 과제이다.12 장 애물 보행 중 적절한 동작 생성을 위한 정보처리와 이를 기반으로 한 신체 균형 및 하지 제어의 실패는 낙상 발생의 가장 큰 원인 중 하나가 되고 있다. ${ }^{13}$ 이러한 자세 조절 및 신체의 균형 유지, 그리고 사지의 협 응과 새로운 환경에 대한 적응 등에 직접적으로 관여하는 소뇌에 손 상을 입은 환자의 경우 장애물 보행은 도전적이며 위협적인 동작 과 제라고 할 수 있다.

이에 본 연구에서는 과제 특수성 원리를 적용한 운동중재 훈련이 소뇌성 운동실조증 환자들의 장애물 보행능력에 미치는 영향을 정 량적이고 객관적으로 규명하는 데 그 목적을 두었다. 장애물 보행기 능의 향상을 위한 주요한 중재 원칙으로는 동적 균형과 자세 정렬 및 유지, 지지하는 하지로의 안정적인 무게 중심 이동, 그리고 조화로운 하지 분절의 걸음 동작과 같은 기본적인 구성 요소의 훈련에 초점을 맞추어 재활 프로그램을 구성하고 진행하였다. 궁극적으로, 타당성 이 입증된 임상적 검사와 보행의 운동학적 분석을 통해 얻어진 객관 적 증거를 바탕으로 하여 운동실조증 장애에 최적화된(ataxia-specific) 장애물 보행 재활의 전략 및 지침을 제공하고자 한다.

\section{연구방법}

\section{1. 연구대상}

본 연구의 대상자들은 서울의 K대학교 병원 신경과에 내원하여 소뇌 질환으로 인해 운동학적 이상 증상인 운동실조증(ataxia)을 보인 환 자들로서 연구의 목적을 이해하고 자발적으로 실험에 참여할 의향 을 보인 13명(남자 5명, 여자 8 명, 평균나이: $46.2 \pm 7.4$ 세, 평균유병기간: $5.2 \pm 4.8$ 년)을 선정하였다. 이들 중 뇌졸중이나 종양으로 인해 소뇌의 특정 영역에 발생하는 국소성 병변(focal lesion)을 가진 자는 없었으 며, 유전적 요인으로 인해 소뇌(일부 뇌간과 척수)의 전 영역에 걸쳐 신경세포가 광범위하게 사멸되는 퇴행성 질환으로 진단받은 환자들 을 대상으로 연구를 진행하였다. 실험에 앞서 한국형 간이 정신 상태 검사지(Mini-Mental State Examination)를 통한 평가에서 소뇌 이외의 중추신경계 문제로 인한 인지기능에 이상이 없는 것을 확인하였다. 모든 참가자는 실험참가 전에 실험에 대한 사전 설명을 듣고 참여한 뒤참가동의서를작성하였다.

\section{2. 실험방법}

1) 측정도구

(1) 기능적 임상 측정

(1) 국제협응운동장애평가척도(International Cooperative Ataxia

Rating Scale, ICARS)

ICARS는 1997년 세계신경성운동실조증연구협회(the World Federation of Neurology Ataxia Research Group)에 의해 개발되었으며, 소뇌 의 손상으로 인한 운동실조증의 증상을 정량화하기 위한 검사지이 다. ${ }^{14}$ 이 임상검사에서는 자세와 보행 장애(postural and gait) 7 항목(총 점 34점), 기능적 운동 능력(kinetic functions) 7항목(총점 52)점, 언어 장애(speech disorders) 2항복(총점 8점), 안구운동장애(oculomotor disorders) 3 항목(총점 6)으로 총 19항목(총 100점)으로 구성되어 있다. 기능별 점수는 최하점수 0 점에서 최고 점수는 각 항목별로 1 점에서 8 점으로 이루어져 있으며, 정상인 경우 0 점, 그리고 증상의 정도에 따 라 높은 점수를 적용하여 평가하는 것으로써 평가 점수가 낮을수록 기능적 장애가 적다는 것으로 판단하는 척도이다.

\section{(2) 버그 균형 척도(Berg Balance Scale, BBS)}

버그 균형 척도는 앉기, 서기 및 자세 변화 등 3 개의 영역(총 14 개 항 목)으로 이루어진 균형 척도로서 최소 0 점에서 최고 4 점을 적용하며 총 56점으로 평가되는 척도이다. 이 척도는 균형 능력이 좋을수록 점 수가 높게 나타나며, 고령자들과 뇌졸중 환자 그리고 외상성 뇌병변 환자 등의 균형 능력에 대한 기능적 평가로 활용되고 있다.15 
(3) 낙상 효능감 척도(Fall Efficacy Scale, FES)

Tinetti 등'16에 의해서 개발된 척도로서 기존의 '기존의 낙상이 두려운 가라는 단순한 단답형의 이분법적인 측정이 임상과 연구 목적에 적 절하지 못함을 고려하여 낙상과 관련된 균형 저하와 낙상에 대한 자 신감에 대해 10 개의 문항으로 수치화한 척도이다. "전혀 할 수 없다" 를 1점으로 하여 “아주 잘 할 수 있다" 10 점까지 구성된 것을 사용하 였으며, 점수가 높을수록 일상생활에서 활동을 잘 수행할 수 있다는 의미로 해석되며, 낙상에 대한 자신감이 높다고 할수 있다.

\section{(2) 장애물 보행 측정}

본 연구에서는 운동학적 측정을 위해 두 가지의 실험 장비를 사용하 였다. 첫째, 장애물 보행시 운동학적 특성을 측정하기 위하여 OptiTrack (NaturalPoint Inc. Oregon, USA) 3차원 동작분석 시스템을 사용 하였다. 참가자들의 움직임은 시스템과 연결된 마커 45 개를 통해서 $\mathrm{x}$ 축, $y$ 축 그리고 $\mathrm{z}$ 축 선상에서 장애물을 넘을 때 거리와 방향, 발(중족 골) 동작의 높이 등 운동학적 자료를 $3 \mathrm{D}$ 영상으로 측정하였다. 측정 빈도는 $100 \mathrm{~Hz}$ 로 설정하였으며, 수집된 데이터는 연결된 컴퓨터로 저 장되었다. 둘째, 이동 경로(총 $8 \mathrm{~m}$ )에 설치할 장애물은 스포츠 현장에 서 트레이닝을 위해 사용하는 조립식 허들을 활용하였으며, 장애물 의 높이는 일상생활에서 접하는 보도블록 또는 장난감 등의 높이에 해당하는 $15 \mathrm{~cm}$ 로 설정하였다(평균 하지 길이의 약 $18.7 \%$ ). 장애물은 약한 접촉에도 쉽게 탈착되는 것으로 환자의 안전에 위협을 가하지 않는 도구로 선정하였다.

장애물 보행에서 나타나는 피험자의 하지 제어 전략과 움직임의 형태와 관련된 측정변인은 다음과 같다. 첫째, 장애물을 넘는 동안 하지의 제어 패턴을 정량화한 변인으로 장애물과 넘는 발 사이의 수 직거리 $(\mathrm{cm})$ 인 장애물 통과 높이(foot clearance), 둘째, 환경적 요구와 어떻게 상호작용을 하고 있는지를 보여주는 변인으로 장애물을 넘 기 전 장애물과 발까지의 수평거리인 이륙거리(pre-obstacle distance), 셋째, 하지의 제어를 통한 발 정치(placement) 능력을 측정하는 변인 으로 장애물을 넘은 후에 장애물과 발의 착지점까지의 수평거리인 착지거리(post-obstacle distance), 넷째, 외적 정보처리 및 운동 계획에 소요된 시간을 측정하는 변인으로 장애물 넘기 전 선행하는 발이 지 면에 닿은 후 장애물을 넘기 위해 바닥에서 떨어지기 전까지의 지체 시간(pre-obstacle delay time), 다섯째, 장애물을 넘는데 소요된 총 시 간인 장애물 보행 시간(obstacle crossing time), 여섯째, 장애물을 넘는 동안 자세의 안정성을 측정하기 위한 몸의 무게 중심(Center of gravity, COG) 좌우 방향 변위(COG range)와 각 걸음값의 표준편차를 근 거로 계산한 가변성(COG variability), 일곱째, 장애물을 넘는 동안 동 작의 단속성(decomposition)을 측정하기 위하여 COG 곡선의 가속도 궤도를 기반으로 한 영점 교차(zero crossing) 점수를 구하였다.

\section{2) 중재훈련 프로그램}

장애물 보행 훈련은 매회 90분씩, 총 8 주에 걸쳐 매주 2 일씩 진행하 였다. 본 연구에서의 과제-특수적 운동치료 프로그램은 장애물 보행 주기를 분절화된 형태로 세분화하여 훈련하는 데 초점을 두었으며, 재학습 과정을 통해 자연스러운 하나의 연속적인 움직임으로 발전 해 가도록 유도하였다. 우선, 환자가 바로 선 자세에서 안전하게 신체 의 무게중심을 이동하는 것으로 훈련을 시작했다. 첫 단계에서 환자 는 장애물 앞에서 하지를 어깨 넓이로 벌려 양 발에 체중을 균등하 게 분포한 상태로 서있도록 했다. 환자가 편안하고 안정적인 자세로 서고 나면, 두번째 단계에서는 지지하는 다리 쪽으로 체중이 완전히 옮겨질 때까지 몸의 무게 중심을 옆으로 천천히 이동하도록 지시했 다. 이때 움직임에 따른 몸의 무게 중심의 변화를 의식적으로 인지하 며 제어하는데 중점을 두었다. 체중이 한 다리에 실린 후에는 움직임 을 멈추고 몸의 무게중심과 하지와 체간 등의 신체의 위치를 스스로 인지 및 평가하여 정렬하도록 하였다. 지지하는 발을 기준으로 신체 균형 및 자세의 안정성이 유지된 다음 세번째 단계에서는 지지하는 발의 앞쪽으로 체간 또는 몸 전체를 약간 숙여서 체중이 지지하는 발의 앞 부분(중족골)에 위치하게 하였으며, 이 때 반대 발은 가볍게 땅에 닿은 상태에서 무릎을 약간 굴곡시킨 자세로 안정되게 서있도 록 하였다. 그런 다음 네번째 단계에서는 입각 하지로 신체의 균형을 유지하면서 유각 하지의 발을 조심스럽게 들어 올린 후 장애물을 넘 게 하였다. 이때 신체의 동요를 최소화 하면서 장애물 넘어로 발을 정 치하도록 하였다. 만약 신체 불안정성이 증가하거나 균형 손실이 일 어날 경우 환자들은 움직임을 멈추거나 자세를 낮추고 안정적인 자 세에서 다시 시작하도록 요구 받았다. 그런 다음 다섯번째 단계에서 는 체간 또는 몸 전체를 외측 및 전방으로 숙여 체중이 전방에 놓인 발 쪽으로 완전히 이동하도록 하였다. 이 때 전방으로 자세의 안정성 을 유지하면서 먼저 유각 하지의 발뒤꿈치를 바닥에서 뗀 후 다리를 들어 올려 입각하고 있는 발 옆에 부드럽게 놓도록 지시하였다. 그런 다음 첫 단계에서와 마찬가지로 양 발에 체중을 균등하게 분포한 상 태가 되도록 몸의 무게 중심을 가운데로 이동하고 신체를 안정화함 으로써 동작을 마무리 지었다. 이러한 발 디딤 과정을 반대편 하지에 도 적용하여 반복하였다.

각 보행 단계의 훈련 동안 환자들의 주의는 의식적 지각과 신체 무 게중심의 안정화, 체간 및 하지 정렬의 제어에 집중하도록 지시하였 다. 필요시 실험보조자는 환자의 손을 잡고 체중을 지지해 주었으며, 적합한 보행 패턴을 인지하도록 돕기 위해 구두지시 및 피드백, 그리 고 신체적 가이던스를 제공하였으나, 훈련과정이 경과함에 따라 스 스로 수행할 수 있도록 점차적으로 이러한 개입을 최소화하였다. 


\section{3) 자료분석}

수집된 자료는 SAS 9.1 통계 프로그램을 이용하여 평균과 표준편차 를 산출하여 분석하였다. 임상검사 데이터는 윌콕슨 부호순위 검정 (Wilcoxon signed rank test)을 사용하여 훈련 전후의 효과를 검증하였 으며, 장애물 보행과 관련된 정량화된 운동학적 데이터는 대응표본 T검증(paired t-test)을 사용하여 측정변인을 검증하였다. 통계학적 유 의수준은 $\alpha=.05$ 로 설정하였다.

\section{결 과}

\section{1. 운동중재 전후 임상검사 비교}

참가자들의 과제 특수적 장애물 보행 훈련 프로그램 전후 국제협응 운동장애평가척도(ICARS)는 다음과 같다(Table 1). 운동중재 프로그 램 참가 전에 비해 약 3.26 점 정도의 감소되는 경향을 보였으며, 부분 적으로 통계적 유의수준까지 도달하였으나 유의한 차이를 나타내지 는 않았다. 참가자들의 균형 능력을 평가하기 위한 버그 균형 척도 (BBS) 점수는 운동 프로그램 참가 후 약 8.55점 향상되었으며, 통계적 으로 유의한 차이가 나타났다. 하지만 낙상의 두려움을 평가하기 위 한 낙상 효능감 척도(FES) 점수는 참가 전후의 변화에서 유의한차이 가 나타나지 않았다.

Table 1. Means and standard errors of clinical outcomes

\begin{tabular}{lcccc}
\hline & Pre-training & Post-training & $z$ & $p$ \\
\hline ICARS & $40.51 \pm 8.57$ & $37.25 \pm 7.25$ & 1.85 & 0.063 \\
Berg balance scale & $32.65 \pm 11.23$ & $41.20 \pm 9.45$ & 2.21 & 0.027 \\
Fall efficacy scale & $6.56 \pm 1.91$ & $6.96 \pm 1.53$ & 1.06 & 0.225 \\
\hline
\end{tabular}

ICARS, International Cooperative Ataxia Rating Scale.

\section{2. 운동중재 전후 장애물 보행 비교}

훈련 프로그램 참가자들의 장애물 보행 평가에서 측정된 변인의 분 석 결과는 다음과 같다(Table 2). 장애물 통과 높이(foot clearance)는 운동 프로그램 참가 전에 비해 약 $8.51 \mathrm{~cm}$ 감소하였으며, 통계적을 유 의한 차이를 보였다. 장애물을 넘기 직전에 따르는 발을 딛는 위치와 장애물간의 거리인 이륙거리(pre-obstacle distance)는 프로그램 참가 후 약 $9.13 \mathrm{~cm}$ 의 유의한 증가를 나타내었다. 장애물을 넘은 후의 발착 지점과 장애물까지의 착지거리(post-obstacle distance)는 참가 후 약 $8.99 \mathrm{~cm}$ 의 유의한 증가를 보였다. 장애물을 넘기 직전에 소요된 지체 시간(pre-obstacle delay time)는 약 1.35 초 정도 유의하게 감소하였다. 그리고, 전체 장애물 보행 시간(obstacle crossing time) 또한 운동 프로 그램 참가 후약 2.6 초 정도 유의한 감소를 보였다.

장애물 보행 중 신체 균형 및 자세의 제어 능력을 평가하기 위한 신 체 무게 중심의 좌우방향 동요 범위(COG range)를 분석한 결과 (Figure 1A), 운동 프로그램 참가 전후에 유의한 차이가 나타났다 $(\mathrm{p}<0.05)$. 또한 각 걸음에서 나타난 무게 중심의 변위값의 표준편차 를 근거로 무게 중심의 가변성(variability)을 분석한 결과(Figure 1B), 프로그램 참가 후 통계적으로 유의한 감소를 보였으며 $(\mathrm{p}<0.05)$, 이는 장애물 보행과 관련하여 환자들의 자세의 안정성이 높아진 것으로 볼 수 있다. 그리고, $\mathrm{COG}$ 곡선의 가속도 궤도를 기반으로 영점 교차 (zero crossing)의 횟수를 분석한 결과(Figure 1C), 프로그램 참가 후 감

Table 2. Means and standard errors of obstacle crossing variables

\begin{tabular}{lrrrc}
\hline & Pre-training & Post-training & $\mathrm{t}$ & $\mathrm{p}$ \\
\hline Foot clearance $(\mathrm{cm})$ & $22.23 \pm 2.68$ & $13.72 \pm 1.57$ & 12.07 & 0.001 \\
Pre-obstacle distance $(\mathrm{cm})$ & $15.24 \pm 6.52$ & $24.37 \pm 3.04$ & 8.86 & 0.007 \\
Post-obstacle distance $(\mathrm{cm})$ & $22.42 \pm 5.48$ & $31.41 \pm 4.03$ & 10.77 & 0.002 \\
Pre-obstacle dealy time $(\mathrm{s})$ & $2.16 \pm 0.25$ & $0.81 \pm 0.16$ & 12.09 & 0.001 \\
Obstacle crossing time $(\mathrm{s})$ & $12.11 \pm 1.84$ & $9.51 \pm 0.92$ & 3.08 & 0.021
\end{tabular}

COM Displacement

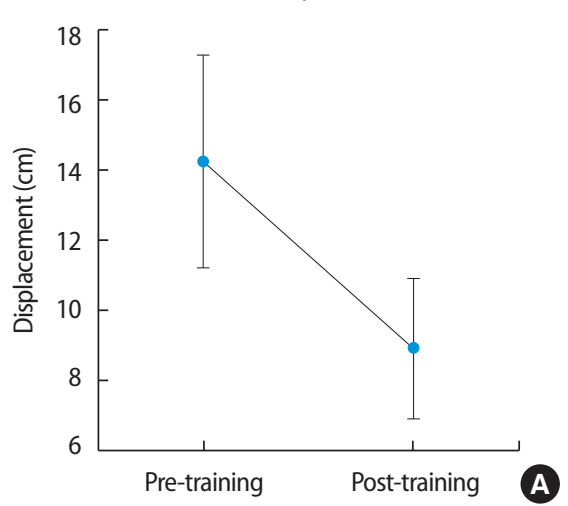

COM Standard diviation

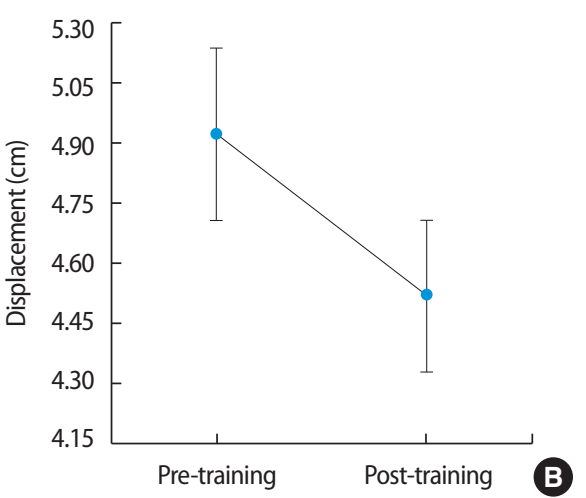

Zero crossings

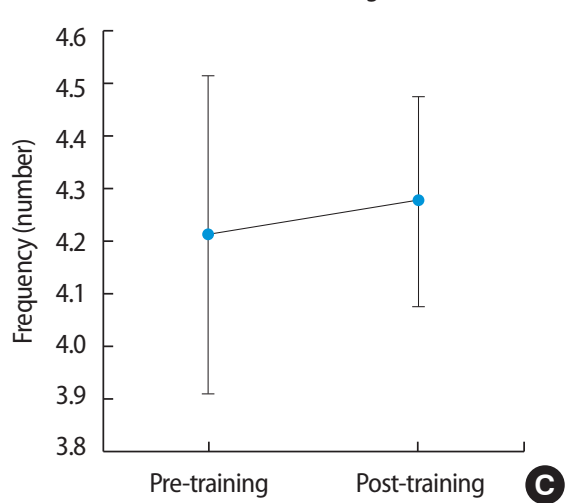

Figure 1. The average and the standard error of center of mass (COM) displacement (A), variability of COM (B), and zero crossings (C) at pre- and post-training test. 
소되는 경향을 보였으나 통계적으로 유의하지는 않았다.

\section{고 찰}

소뇌의 손상은 동작의 협응과 균형 제어의 결손, 그리고 증가된 보행 가변성 등의 운동 장애를 유발한다. 이러한 운동기능 이상은 장애물 보행과 같은 비교적 복잡하고 보다 기능적인 이동운동의 수행을 더 욱 어렵게 만들며, 따라서 환자들에게 있어서 보다 안전하고 독립적 인 보행능력을 향상시킬 수 있는 효과적인 재활 운동프로그램 개발 의 필요성이 대두되고 있다. 본 연구에서는 소뇌성 운동실조증 환자 들을 대상으로 하여 과제 특수성 원리를 적용하여 장애물 보행 재활 의 효과를 검증하고자 하였다.

먼저 과제 특수적 장애물 보행 훈련 프로그램 참가를 통한 장애물 통과높이의 변화에서 유의한 감소를 나타냈다. 장애물과 넘는 발 사 이의 통과높이는 장애물과의 접촉으로 인한 낙상에 대한 가능성을 줄이고 안전성을 높이기 위한 전략으로써 균형 장애가 있는 경우 흔 히 나타나는 특징이다. ${ }^{17}$ 특히 소뇌질환 환자의 경우 다관절 움직임 제어와 협응의 저하로 과제 수행시 동작이 과도하게 나타나거나 의도 한 목표물을 지나치는 것과 같은 운동거리조절이상(dysmetria) 증상 으로 인해 더욱 두드러지게 나타난다..$^{18}$ 본 연구에서 제시한 훈련 프 로그램 참가를 통해 장애물 통과높이가 감소되는 결과가 나타난 것 은 소뇌성 운동실조증 환자들의 근육간 또는 사지 분절간 협응 움직 임 및 기능적 보행 능력의 회복에 긍정적인 변화가 나타난 것으로 해 석할 수 있다. 즉, 장애물의 특성(높이, 너비, 거리 등)을 지각하고 그에 따라 하지 관절의 협응을 통한 굴곡 움직임을 보다 효율적이고 안전 하게 제어하는 능력에 영향을 주었다고 볼 수 있다.

장애물을 넘기 전 장애물과 발까지의 수평거리인 이륙거리와 장 애물을 넘은 후에 장애물과 발의 착지점까지의 수평거리인 착지거리 는 운동 프로그램 참가 후 유의한 증가를 보였다. 지지하는 발을 비교 적 장애물에 가깝게 위치시키는 전략은 장애물 보행시 한발로 균형 을 유지하는 시간을 줄여 균형 저하로 인한 낙상 두려움을 줄이고 자 세 안정성을 확보하기 위한 행동 전략으로 보인다. 하지만 궁극적으 로 보행 속도를 줄이고 장애물 통과높이를 증가시키며 장애물에 접 촉할 가능성을 높이게 된다. ${ }^{19}$ 사후 검사에서 발의 이륙거리와착륙거 리가 증가된 결과는 장애물을 넘는 동안 전체적인 하지의 궤도 및 동 작의 유연성이 증가한 것으로 볼 수 있으며, 장애물 보행시 하지 움직 임의 시. 공간적 효율성과 동적 균형능력이 증대된 것으로 해석할 수 있다.

장애물을 넘기 전 동작의 지체가 나타나는 것은 주로 수행하는 동 작과제가 복잡하거나 높은 수준의 제어 요구가 있을 때, 또는 수행자 가 낙상의 두려움을 느끼는 환경에서 나타난다. ${ }^{20}$ 본 연구의 참가자
들은 운동 프로그램 참가 후 이러한 지체 시간이 감소되는 결과를 보 여 주었다. 이는 평지 보행 후 장애물을 넘는 구간으로 보행이 전환되 는 동작 연결에 소요되는 시간이 감소되었음을 의미한다. 또한 장애 물 보행을 수행하는데 필요한 환경정보를 인지하고 이를 기반으로 적절한 운동을 계획하고 실행하는 정보처리 능력이 향상되었다고 볼 수 있다. ${ }^{21}$ 더불어 이러한 장애물 직전에서 나타나는 동작 지체 시 간의 감소는 장애물을 넘는데 소요된 총 장애물 보행 시간의 감소에 도 크게 기여한 것을 보인다.

장애물 보행시 몸의 안정성 변화를 관찰하기 위해 신체 무게중심 (COG)의 동요 정도를 측정한 결과, 무게중심의 좌우 방향 변위와 각 걸음값의 표준편차를 근거로 계산한 가변성이 운동 프로그램 참가 후 유의하게 감소되었다. 하지만 영점 교차 점수에는 변화가 나타나 지 않아 연속적이며 유연한 동작과제의 수행능력에는 영향을 주지 않았다. 이동운동 수행 중 자세 동요와 동작 가변성의 증가는 소뇌질 환 환자들에게 대표적으로 나타나는 운동이상 증상이며, 이는 소뇌 기능의 결함으로 말미암아 발생한 운동학적 장애와 균형 능력의 저 하로 인해 야기된 것으로 볼 수 있으며, 이러한 원인들로 낙상의 위험 률을 증가 시킬 수 있다.13 본 연구에서 나타난 무게중심의 동요 및 가 변성의 유의한 감소는 훈련 프로그램 참가를 통해 장애물 보행시 동 적 균형능력이 증가함과 동시에 동작의 가변성이 낮아지고 동작 패 턴의 일관성이 높아졌다고 볼 수 있다. 이는 복잡하고 보다 기능적인 운동수행을 요구하는 장애물 보행에서 신체의 자세 및 동작의 제어 능력이 향상되었다는 점에서 의미가 있는 결과라 할 수 있다.

앞에서 관찰된 이러한 운동학적 변화는 임상검사 결과에서도 반 영되어 나타났다. 비록 낙상에 대한 심리적 두려움에 대한 평가(FES) 에서는 큰 변화가 나타나지 않았으나, 환자들의 자세와 보행, 그리고 기능적 운동능력의 통합 평가(ICARS)와 균형능력의 평가(BBS)에서 는 전반적으로 향상되는 경향성을 보였다. 결론적으로, 본 연구에서 제시한 과제 특수성 원리를 기반으로 한 운동중재 훈련이 장애물에 대한 감각적 지각과 적절한 동작 생성을 위한 운동 계획 등의 정보처 리 능력, 그리고 신체의 무게중심과 자세에 대한 인지를 통한 재학습 과정이 정상적인 장애물 보행능력의 획득과 신체의 안정성 증가에 기여한 것으로 판단된다. 추후 연구에서는 통제집단(control group)과 의 비교연구를 통해 보다 객관적으로 재활 프로그램의 효과를 검증 할 필요가 있다. 또한 뇌영상촬영 분석 등을 통해 행동적 변화 이면에 나타나는 신경계 변화 및 기제에 대한 이해를 바탕으로 보다 효과적 인 재활의 원리와 전략을 규명하는 시도가 이루어져야 할 것이다.

\section{ACKNOWLEDGEMENT}

이 논문은 2012년 정부(교육과학기술부)의 재원으로 한국연구재단 
의 지원을 받아 수행된 연구임 (NRF-2012S1A5A2A01021017).

\section{REFERENCES}

1. Earhart GM, Bastian AJ. Selection and coordination of human locomotor forms following cerebellar damage. J Neurophysiol. 2001;85(2):75969.

2. Paulsen EK, Friedman LS, Myers LM, et al. Health-related quality of life in children with Friedreich ataxia. Pediatr Neurol. 2010;42(5):335-7.

3. Hong SI, Bang DH, Shin WS. Effects of side walking training with elastic-band on gait and balance of stroke patients. J Kor Phys Ther. 2014; 26(5):372-8.

4. Jeong HY, Choi JD. The Effects of vestibular sensory stimulation training on balance and gait in the patients with stroke. J Kor Phys Ther. 2014; 26(5):365-71.

5. Shim HB, Cho HY, Choi WH. Effects of the trunk stabilization exercise on muscle activity in lumbar region and balance in the patients with hemiplegia. J Kor Phys Ther. 2014;26(1):33-40.

6. Kim JH. The effects of whole body vibration exercise on balance and lower extremity muscle activity in stroke patients. J Korean Soc Phys Ther. 2013;25(5):266-72.

7. Ilg W, Bastian AJ, Boesch S, et al. Consensus paper: management of degenerative cerebellar disorders. Cerebellum. 2014;13:248-68.

8. Miyai I, Ito M, Hattori N, et al. Cerebellar ataxia rehabilitation trial in degenerative cerebellar diseases. Neurorehabil Neural Repair. 2012;26: 515-22.

9. Ilg W, Timmann D. Gait ataxia-specific cerebellar influences and their rehabilitation. Mov Disord. 2013;28:1566-75.

10. Plautz EJ, Milliken GW, Nudo RJ. Effects of repetitive motor training on movement representations in adult squirrel monkeys: Role of use versus learning. Neurobiol Learn Mem. 2000;74(1):27-55.

11. Bayona NA, Bitensky J, Salter K, et al. The role of task-specific training in rehabilitation therapies. Top Stroke Rehabil. 2005;12(3):58-65.

12. Berard JR, Vallis LA. Characteristics of single and double obstacle avoidance strategies: A comparison between adults and children. Exp Brain Res. 2006;175(1):21-31.

13. Bart PC, van de Warrenburg, Janneke AG, et al. Falls in degenerative cerebellar ataxias. Mov disord. 2005;20(4):497-508.

14. Trouillas P, Takayanagi T, Hallett M, et al. International cooperative ataxia rating scale for pharmacological assessment of the cerebellar syndrome. J Neurol Sci. 1997;145:205-11.

15. Berg KO, Wood-Dauphinee SL, Williams JI. The balance scale: reliability assessment with elderly residents and patients with an acute stroke. Scand J Rehabil Med. 1995;27:27-36.

16. Tinetti ME, Richman D, Powell L. Falls efficacy as a measure of fear of falling. J Gerontol. 1990;45(6):239-43.

17. Lu TW, Chen HL, Chen SC. Comparisons of the lower limb kinematics between young and older adults when crossing obstacles of different heights. Gait Posture. 2006;23(4):471-9.

18. Bastian AJ, Zackowski KM, Thach WT. Cerebellar ataxia: torque deficiency or torque mismatch between joints? J Neurophysiol. 2000;83(5): 3019-30.

19. Said CM, Goldie PA, Patla AE, et al. Effect of stroke on step characteristics of obstacle crossing. J Neurophysiol. 2001;82(12):1712-9.

20. Palliyath S, Hallett M, Thomas SL, et al. Gait in patients with cerebellar ataxia. Mov Disord. 1998;13(6):958-64.

21. Krell J, Patla AE. The influence of multiple obstacles in the travel path on avoidance strategy. Gait Posture. 2002;16(1):15-9. 